\title{
UK government's delay on plain tobacco packaging: how much evidence is enough?
}

\author{
Early findings from Australia add to a rapidly growing body of research
}

\author{
Crawford Moodie senior research fellow ${ }^{123}$, Linda Bauld professor of health policy ${ }^{13}$, Martine Stead \\ deputy director ${ }^{1}$
}

${ }^{1}$ Institute for Social Marketing, University of Stirling, Stirling FK9 4LA, UK; ${ }^{2}$ Centre for Tobacco Control Research, University of Stirling; ${ }^{3} \mathrm{Centre}$ for Tobacco and Alcohol Studies, University of Stirling

In the wake of the UK government's announcement on 12 July that its decision on plain (standardised) tobacco packaging would be delayed until evidence emerged from Australia, Wakefield and colleagues report timely findings from a study exploring the early effects of plain packaging in Victoria. ${ }^{12}$ Conducted during the phase-in period, when plain and branded packs were concurrently on sale, the study found that smokers who used plain packs were more likely than smokers who used fully branded packs to perceive their cigarettes to be less satisfying and poorer quality, were more supportive of plain packaging, and were more likely to think about and to prioritise quitting.

These findings extend what was already known about standardised packaging but in a market where plain packs are now on sale. That the appearance of packs influenced users' perceptions of the products is supported by the systematic review commissioned to inform the UK government's consultation on standardised packaging, ${ }^{3}$ as well as subsequent research, ${ }^{4}$ the marketing literature, ${ }^{5}$ and tobacco industry internal documents. ${ }^{6}$

Similarly, the Victoria study's finding that smokers who used plain packs were significantly more likely than smokers of branded packs to have thought about quitting at least once a day in the past week and to rate quitting as a higher priority is consistent with past research. ${ }^{34}$ Desire and intention to quit are reliable predictors of whether someone tries to stop smoking, ${ }^{78}$ and studies of smokers who use cessation services have shown that high motivation to stop is an important determinant of success in quitting. ${ }^{9}$ Wakefield and colleagues' finding of an increased desire to quit among plain pack users can be linked with anecdotal evidence from Australia that calls to the Quitline in Victoria increased after the introduction of plain packaging. ${ }^{10}$ Given that encouraging smokers to stop is a public health policy priority in the United Kingdom and elsewhere, these early findings from Australia provide some support for this aim. Whether they are enough to influence UK policy is unclear.
They do, however, add to a very rapidly growing body of evidence. Standardised packaging in the UK was first considered as a possible policy measure in the previous Labour government's consultation on the future of tobacco control in 2008, which cited four studies from North America. By 2011, when the current government launched a consultation on the issue, its evidence review included 37 studies, six of which were from the UK. ${ }^{3}$ Since that review at least 12 additional studies have been published, including three more from the UK. ${ }^{411} 12$ This growing body of research is consistent in its findings: that plain packaging would reduce the appeal of tobacco products to consumers; would increase the effectiveness of health warnings; and would reduce the ability of packaging to mislead consumers about the harmful effects of smoking.

Two days before the UK government's announcement on standardised packaging, the European Parliament's Committee on the Environment, Public Health and Food Safety endorsed updating the current Tobacco Products Directive, which sets the tobacco packaging and labelling requirements for the European Union. The committee supported pictorial health warnings covering $75 \%$ of the front and back of tobacco packaging and a ban on slim "lipstick type" cigarette packs. If approved, the move to large pictorial warnings on packs and a ban on slim packs should help reduce pack appeal, enhance the visibility of warnings, and disrupt tobacco companies' ability to communicate with consumers. However, these changes would not stop other forms of packaging innovation to attract consumers. Nor would they prevent manufacturers using the design of packaging and branding to detract from health warnings or prevent consumers being confused about harms of the products as a consequence of pack colour. As outlined in the Framework Convention on Tobacco Control, only plain packaging can do this. ${ }^{13} 14$ 
Most smokers become addicted in childhood, and although these findings from Australia concern adults, standardised tobacco packaging also aims to protect children from smoking. Figures just released show that the prevalence of smoking among children continues to fall in England. ${ }^{15}$ In fact, the prevalence of ever smoking and of regular smoking among boys and girls has steadily fallen since the UK government introduced a battery of tobacco control measures as part of a comprehensive strategy initially outlined in the 1998 white paper Smoking Kills. There is no guarantee that this decline will continue if a tobacco control strategy is not sustained. As packaging has become the key marketing and communications tool for tobacco companies since the ban on tobacco advertising, promotion, and sponsorship, standardised packaging would appear to be a logical next step.

Competing interests: The University of Stirling's Institute for Social Marketing and Centre for Tobacco Control Research get research funding from Cancer Research UK. The authors state no competing interests other than the institutional funding received from Cancer Research UK.

bmj.com Observations: Cameron's cave-in on plain packaging is a boost to industry (BMJ 2013;346:f3069, doi:10.1136/bmj.f3069)

Commissioning and peer review: Commissioned, not externally peer reviewed.

1 Wakefield M, Hayes L, Durkin S, Borland R. Introduction effects of the Australian plain packaging policy on adult smokers: a cross-sectional study. BMJ Open 2013;3:e003175.
2 Kmietowicz Z. Plain packaging seems to increase thoughts about quitting smoking. $B M J$ 2013;347:44665.

3 Moodie C, Stead M, Bauld L, McNeill A, Angus K, Hinds K, et al. Plain tobacco packaging: a systematic review. Institute for Social Marketing, University of Stirling, 2012.

4 Moodie C, Mackintosh AM. Young adult women smokers' perceptions of using plain cigarette packaging: a naturalistic approach. BMJ Open 2013;3:e002402.

5 Silayoi $P$, Speece $M$. The importance of packaging attributes: a conjoint analysis approach Br Food J 2007:41:1495-517.

6 Centre for Tobacco Control Research. The packaging of tobacco products. Centre for Tobacco Control Research, University of Stirling, 2012.

7 Borland R, Yong H-H, Wilson N, Fong GT, Hammond D, Cummings KM, et al. How reactions to cigarette pack health warnings influence quitting: findings from the ITC four country survey. Addiction 2009;104:669-75.

8 Smit E, Fidler J, West R. The role of desire, duty and intention in predicting attempts to quit smoking. Addiction 2011;106:844-51.

9 Ferguson J, Bauld L, Chesterman J, Judge K. The English smoking treatment services: one-year outcomes. Addiction 2005;100;59-69.

10 World Health Organization. Reducing the appeal of smoking: first experiences with Australia's plain tobacco packaging law. 2013. www.who.int/features/2013/australia tobacco packaging/en.

11 Ford A, Moodie C, Mackintosh AM, Hastings G. How adolescents perceive tobacco packaging and possible benefits of plain packaging. Educ Health 2013;31. http://sheu. org.uk/x/eh312af.pdf.

12 Maynard O, Munafó M, Leonards U. Visual attention to health warnings on plain tobacco packaging in adolescent smokers and non-smokers. Addiction 2013;108:413-19.

13 World Health Organization. Elaboration of guidelines for implementation of Article 11 of the Convention. Third session of the Conference of the Parties to the WHO Framework Convention on Tobacco Control. Durban, South Africa, 17-22 Nov 2008. www.who.int/ fctc/guidelines/article_11.pdf.

14 World Health Organization. Elaboration of guidelines for implementation of Article 13 of the Convention. Third session of the Conference of the Parties to the WHO Framework Convention on Tobacco Control. Durban, South Africa, 17-22 Nov 2008. http://apps.who. int/gb/fctc/PDF/cop3/FCTC COP3 9-en.pdf.

15 Health and Social Care Information Centre. Smoking, drinking and drug use among young people in England in 2012: a survey carried out for the Health and Social Care Information Centre by NatCen Social Research and the National Foundation for Educational Research. 2013.

Cite this as: BMJ 2013;347:f4786

(c) BMJ Publishing Group Ltd 2013 